\title{
Bazı Modern Buğday Varyeteleri ve Yerel Çeşitlerin Melez Populasyonlarında Koleoptil Uzunluğunun Kalıtımı
}

\author{
Fatih ATEŞ ${ }^{1}$ Deniz IŞTiPLILER ${ }^{1} \quad$ *Fatma AYKUT TONK ${ }^{1}$ Alex MORGOUNOV ${ }^{2}$ \\ Beyhan AKIN ${ }^{2} \quad$ Muzaffer TOSUN ${ }^{1}$ \\ ${ }^{1}$ Ege Üniversitesi Ziraat Fakültesi Tarla Bitkileri Bölümü, İzmir \\ ${ }^{2}$ CIMMYT - Ankara, Türkiye \\ *Sorumlu yazar e-posta (Corresponding author; e-mail): fatma.aykut@ege.edu.tr
}

\section{Öz}

Koleoptil uzunluğu buğdayda ekim derinliğini belirleyen önemli bir faktördür. Dünyada yaygın kullanılan gibberellik aside duyarsız Rht-B1b (Rht1) ve Rht-D1b (Rht2) genleri bitki boyu ile beraber koleoptil uzunluğunda kısalmaya neden olmaktadır. Çalışmada koleoptil uzunluğu kalıtımının incelenmesi amacıyla kısa koleoptilli iki modern buğday varyetesi (KS82142/PASTOR; PYN/BAU/3/AGRI/BJYI/VEE) ile beş yerel çeşit (SAR30; RASAD; ICDW-9246; ICDW-21122; SABALAN) ve uzun koleoptile sahip iki uzun boylu modern varyete (ZARGANA; ELANDS) ebeveyn olarak kullanılmış, resiprokal melezlemeler sonucunda 14 kombinasyon oluşturulmuştur. $F_{1}$ 'lerde koleoptil uzunluğu, primer kök sayısı ve ilk yaprak uzunluğu özellikleri incelenmiş ve özellikler arası ilişkilere bakılmıştır. Çalışma sonucunda, ELANDS varyetesinin orta uzunlukta koleoptil özelliği sergilediği ve girdiği her iki kombinasyonda da koleoptil uzunluğu kalıtımının üstün dominantlık olduğu görülmüştür. Geriye kalan 12 kombinasyonda ise koleoptil uzunluğu kalıtımı eşdeğer (kodominant) ve kısmi dominantlık olarak saptanmıştır. Dolayısıyla daha uzun koleoptilli bitkilerin seleksiyonu ileri generasyonlarda yapılmalıdır. İncelenen özelliklerden koleoptil uzunluğu ve ilk yaprak uzunluğu arasında pozitif ve önemli ilişkinin var olduğu tespit edilmiştir. Primer kök sayısı özelliğinin diğer iki özellikle ilişkisi düşük seviyede ve istatistiksel açıdan önemsiz bulunmuştur.

Anahtar Kelimeler: Ekmeklik buğday, Triticum aestivum, koleoptil uzunluğu, Rht genleri, resiproklu melezleme

\section{Inheritance of Coleoptile Length in Cross Populations of Some Modern Wheat Varieties and Landraces}

\begin{abstract}
Coleoptile length is an important factor determining the sowing depth of wheat. World wide used gibberrellic acid-insensitive dwarfing genes, Rht-B1b (Rht1) and Rht-D1b (Rht2), reduce both plant height and coleoptile length. The purpose of this study was to investigate the mode of inheritance of coleoptile length in crosses of two modern wheat varieties (KS82142/PASTOR and PYN/BAU/3/AGRI/BJYI/VEE) with short coleoptile and five landraces (SAR30; RASAD; ICDW-9246; ICDW-21122; SABALAN) and two modern tall variety (ZARGANA-6and ELANDS) with long coleoptile. Reciprocal crosses were made by using these parents and fourteen combinations were obtained. The $F_{1}$ plants were evaluated for coleoptile length, primary root number, first leaf characteristics. Correlations between the traits were calculated. Variety ELANDS demonstrated intermediate coleoptile and in crosses with short-coleoptile varieties demonstrated over dominance. Intermediate inheritance or partial dominance for coleoptile length were observed in other twelve combinations. Based on this type of inheritance, selection for longer coleoptile length should be conducted in later generations. Significant and positive correlation between coleoptile length and first leaf length was determined. The correlations between primary root number and two other characteristics were observed as low and statistically non- significant.
\end{abstract}

Keywords: Bread wheat (Triticum aestivum L.), coleoptile length, Rht genes, reciprocal cross.

\section{Giriş}

$\mathrm{N}$ orman Borlaug'un 1960'lı yılların başında Japon buğdayı Norin10'dan aktardığı cücelik genleri (Rht) buğday tarihinde bir dönüm noktası niteliği taşımaktadır. Yeşil Devrim'le beraber, buğday geliştirme programlarında yarı cüce buğdaylar üzerine yoğunlaşılmıştır (Singh 
et al. 2001) ve günümüzde tüm dünyada yaygın olarak tarımı yapılmakta olan yüksek verimli modern varyeteler, "Yeşil Devrim Genleri" de denen cücelik genlerinin kullanımı ile elde edilmiştir (Hedden 2010).

Yarı cüce buğdaylar; Rht (Reduced Height) olarak adlandırılan cücelik genlerinin ticari çeşitlere aktarılması sonucu elde edilmiş çeşitlerdir ve genellikle Rht-B1b (Rht1) ve/veya Rht-D1b (Rht2) genlerini taşırlar (Byerlee ve Moya, 1993). Rht1 ve Rht2 genleri pek çok ticari varyetede bazen birlikte de olmak üzere kullanılan gibberellik asite duyarsız cücelik genlerdir ve verim üzerine direkt etkileri vardır (Gale veYoussefian, 1985). Bu genlerin etkisiyle ortaya çıkan kısa boylu yeni bitki tipi pleiotropik etki ya da yakın linkage sayesinde yalnızca yatmaya karşı toleranslı değil aynı zamanda yüksek verimlidir (Hoogendoorn et al. 1988). Cücelik genlerinin modern varyetelere aktarılmasıyla hasat indeksi \%50'nin üzerinde bir oranda keskin bir artıs göstermiştir (Evans 1998). Gibberellik aside duyarsız cücelik genlerine sahip cüce buğdaylar uzun boylu buğdaylara kıyasla daha küçük hücre boyutuna sahiptir (Keyes et al. 1989), dünyada buğday üretilen alanlara geniş olarak adapte edilmişlerdir ve günümüzde gelişmekte olan ülkelerde ekilen buğdayların \%95'i bu gruba dahildir (Heisey and Lantican 1999). Bu cücelik genlerinin varlığı, koleoptillerde görülen dikkate değer kısalığın sorumlusudur (Feather et al. 1968) ve bu durum derine ekimlerde düşük çıkış yüzdesi elde edilmesine neden olur.

Koleoptil, çıkış filizini tohumdan toprak yüzeyine çıkışı esnasında çevreleyip koruyan kılıftır ve ekimden 7-14 gün sonra toprak yüzeyine çıkar (Mızrak, 2011). Buğdayda toprak yüzeyine başarılı bir çıkış için ekim derinliği koleoptil uzunluğundan daha fazla olmamalıdır. Kısa koleoptilli varyetelerin derine ekimi zayıf çimlenme yüzdesine sebep olmaktadır (Pumpa et al. 2013). Tohumun 6-8 cm'den daha derine ekildiği koşullarda, ekimden sonra toprak yüzeyinde kaymak tabakası oluşması durumunda, kısa koleoptile sahip bitkilerin çimlenerek toprak yüzüne çıkması zorlaşır. Söz konusu durumda koleoptil toprak yüzüne erişemeyeceğinden, kından çıkan ilk yaprak, toprak tabakasını delemez ve kendi üzerine kıvrılarak sarı kıvrım durumu meydana gelir. Belli bir süre zarfında toprak yüzüne ulaşamayan bitkiler fotosentez yapamazlar ve bu durum beraberinde ölümü getirir (Sağlam 2010). Koleoptil uzunluğu, özellikle derine ekimin yapıldığı kurak sezonlarda buğday bitkisi için önemli bir karakteristik özelliktir, ekim derinliğini etkiler, genotipe bağlıdır ve uzun koleoptile sahip bitkiler derine ekilebilir (Kirby 1993). Türkiye, dünya üzerinde kuraklığın sürekli bir tehdit unsuru olduğu yarı kurak bir kuşakta yer almaktadır (Devlet Meteoroloji İşleri Genel Müdürlüğü, 2012) ve kurak çevre şartlarında tohumlar nemden yeterince yararlanabilmek için daha derine ekilmelidir.

Görüldüğü üzere, günümüzde yaygın kullanılmakta olan yüksek verimli modern buğday varyeteleri sahip oldukları kısa koleoptil boyları nedeniyle derine ekimin giderek daha da önem kazanacağı kuraklaşan dünyada beklentileri karşılayamayacaktır. Bu nedenle kısa boylu, yüksek verimli ve uzun kolepotil boyuna sahip çeşitlerin geliştirilmesi elzemdir. Bu çalışmanın amacını; CIMMYT (Uluslararası Buğday ve Mısır Geliştirme Merkezi)'ten temin edilmiş kısa koleoptilli modern varyeteler ile uzun koleoptilli yerel çeşitler ve uzun boylu modern varyeteler arasında yapılan melezlemelerin $F_{1}$ generasyonunda, koleoptil uzunluklarının, ilk kök sayılarının ve ilk yaprak uzunluklarının ölçümlenmesi ile söz konusu bu iki özellik ile koleoptil uzunluğu arasındaki ilişkilerin ortaya konması ve koleoptil uzunluğunun kalıtımının incelenmesi oluşturmuştur.

\section{Materyal ve Yöntem}

CIMMYT'e ait kısa koleoptilli iki modern varyete, uzun koleoptilli beş yerel çeşit ve 2 uzun boylu modern varyete ile bunlar arasında yapılmış resiprokal melezlemelerin $F_{1}$ bitkileri bu çalışmanın materyalini oluşturmuştur.Kullanılan ebeveynler ve sahip oldukları cücelik genleri ve bir önceki yıl ölçümlenmiş koleoptil uzunlukları Çizelge 1 ve Çizelge 2'de verilmiştir. Çalışmada kısa koleoptilli ebeveyn olarak kullanılan varyeteler $\mathrm{KK}$, uzun koleoptilli ebeveyn olarak kullanılan varyeteler ise UK harfleriyle kodlanmış ve sıralanmıştır.

Varyeteler arası melezmeler 2012 yilı yetiştirme sezonunda Ege Tarımsal Araştırma Enstitüsü (ETAE) Müdürlüğü'ne ait arazide gerçekleştirilmiştir. Yapılan resiprokal melezlerde, her melez kombinasyonu için ilgili ebeveylerin yedişer adet başağına melezleme işlemi uygulanmış, ebeveyn bitkiler ve melez başakların hasatları yapılmıştır. Melezleme çalışmaları sonucunda 27 melez kombinasyonu elde edilmiştir. Elde edilen tohumlardan her bir resiproklu melezi ve ebeveynlerini kapsayan 14 adet kombinasyon oluşturulmuştur. İlk yedi kombinasyonda (Kombinasyon 1-7) KK1, ikinci 
Ateş et al. "Inheritance of Coleoptile Length in Cross Populations of Some Modern Wheat Varieties and Landraces"

Çizelge 1. Melezlemelerde kısa koleoptilli ebeveyn olarak kullanılan modern varyeteler

Table 1. Modern wheat varieties with short coleoptiles used as parents in crosses

\begin{tabular}{lccc}
\hline Varyete Adı & $\begin{array}{c}\text { Koleoptil Uzunluğu } \\
(\mathrm{cm})\end{array}$ & $\begin{array}{c}\text { Sahip Olduğu } \\
\text { Cücelik Geni }\end{array}$ & Varyete Kod Adı \\
\hline KS82142/PASTOR & 3.44 & $R h t 1$ & KK 1 \\
PYN/BAU/3/AGRI/BJY/VEE & 3.10 & Rht1 & KK 2 \\
\hline
\end{tabular}

Çizelge 2. Melezlemelerde uzun koleoptilli ebeveyn olarak kullanılan yerel çeşitler ve uzun boylu modern varyeteler

Table 2. Modern wheat varieties with short coleoptiles used as parents in crosses

\begin{tabular}{lccc}
\hline $\begin{array}{c}\text { Varyete } \\
\text { Adı }\end{array}$ & $\begin{array}{c}\text { Koleoptil Uzunluğu } \\
(\mathrm{cm})\end{array}$ & $\begin{array}{c}\text { Sahip Olduğu Cücelik } \\
\text { Geni }\end{array}$ & $\begin{array}{c}\text { Varyete Kod } \\
\text { Adı }\end{array}$ \\
\hline SAR-30 & 5.50 & - & UK 1 \\
RASAD & 5.60 & - & UK 2 \\
ZARGANA-6 & 5.58 & Rht8 & UK 3 \\
ICDW-9246 & 6.82 & - & UK 4 \\
ICDW-21122 & 7.18 & - & UK 5 \\
ELANDS & 5.94 & - & UK 6 \\
SABALAN & 5.84 & - & UK 7 \\
\hline
\end{tabular}

yedi kombinasyonda (Kombinasyon 8-14) ise KK2 kısa koleoptilli modern buğday varyeteleri ebeveyn olarak kullanılmıştır.

Her kombinasyon için; kısa koleoptilli ebeveyn, resiprokal melezler ve uzun koleoptilli ebeveyni kapsayan dört adet genotip aşağıdaki gibi oluşturulmuştur. Yalnız Kombinasyon 2'de resiproklu melez yakalanamadığı için ebeveynler ve bir adet melezi kapsayan üç genotip yer almıştır. Örneğin Kombinasyon 1 için ;
1. KK1 (ebeveyn)
2. KK1 x UK1
3. UK1 1 KK1
4. UK1 (ebeveyn)

Her genotip için dörder tohum içeren üç tekerrür hazırlanmıştır. Çalışmada yapılan ölçümlemeler için Hakizimana et al. (2000) ve Bai et al. (2004) tarafından yapılan çalışmalar baz alınmış ve bazı modifikasyonlar yapılmıştır. Her bir tekerrür için, PVC ve kâğıt havlu ile oluşturulmuş düzeneğe tohumlar yerleştirilmiş ve rulo haline getirilmiştir. Oluşturulan rulolar TAGEM'e (Tarımsal Araştırmalar ve Politikalar Genel Müdürlüğü) ait büyütme kabininde 13 gün süreyle $15^{\circ} \mathrm{C}$ sıcaklıkta tutulmuş, 13 gün boyunca yeteri kadar su dolu kap içerisinde ve sürekli gözlem altında bekletilmiştir. 13. gün sonunda koleoptil uzunluğu, primer kök sayısı ve ilk yaprak uzunluğu özellikleri ölçümlenmiştir.

Her özellik için ölçümler aşağıdaki şekilde yapılmıştır:

1. Koleoptil Uzunluğu (cm): Koleoptilin tohumdan çıktığı noktadan son bulduğu noktaya kadar olan kısım ölçülerek cm olarak ifade edilmiştir.

2. Primer Kök Sayısı (adet): Tohumdan çıkan primer köklerin sayılmasıyla elde edilmiştir.

3. İlk Yaprak Uzunluğu (cm): Buğday fidesinin tohumdan çıktığı noktadan ilk yaprağın son bulduğu noktaya kadar olan kısım ölçülerek $\mathrm{cm}$ olarak ifade edilmiştir.

\section{Bulgular ve Tartışma}

Oluşturulan melez kombinasyonların incelenen özelliklere ait kareler ortalaması ve önem düzeyleri Çizelge 3'de verilmiştir. Koleoptil uzunluğu açısından oluşturulan bütün kombinasyonlar kendi aralarında istatistiki olarak farklılıklar göstermişlerdir. Diğer bir incelenen özellik olan primer kök sayısı bakımından oluşturulan kombinasyonlardan 5., 9. ve 11 . kombinasyon haricindekilerde genotipler arasında bir farklılığın olduğu gözlenmiştir. İlk yaprak uzunluğu özelliği açısından ise 1., 3., 5., 10., 12. ve 13. kombinasyonlarda genotipler arasında bir farklılık saptanmamış iken, diğer kombinasyonlarda söz konusu özellik istatistiki olarak farklı bulunmuştur (Çizelge 3). Çalışmada incelenen özellikler arasındaki korelasyon incelendiğinde (Çizelge 4); koleoptil uzunluğunun ilk yaprak uzunluğu ile pozitif ve önemli bir ilişki ( $r=0.964)$ içerisinde bulunduğu ancak primer kök sayısı ile istatistiksel olarak herhangi bir ilişkisinin olmadığı belirlenmiştir. Koleoptil uzunluğu ile ilk yaprak uzunluğu arasında elde ettiğimiz bu korelasyon Chowdhry and Allan (1963)'ın dört farklı melez kombinasyonun $\mathrm{F}_{2}$ generasyonunda yapmış olduğu sonuçlarla uyumluluk göstermiştir. Aynı pozitif ve önemli ilişki Rebetzke ve ark. (2014)'nın oluşturdukları melez populasyonun $\mathrm{F}_{7}$ generasyonunda 12 ve $20^{\circ} \mathrm{C}$ 'de de saptanmıştır. Çalışmamızda elde edilen koleoptil uzunluğu ile ilk yaprak uzunluğu arasındaki bu 
güçlü korelasyon, koleoptil uzunluğu yüksek olan genotiplerde ilk yaprak uzunluğunun daha yüksek oranda ortaya çıkacağını ve yeni gelişen bitkinin daha güçlü genç bitkileri oluşturacağını göstermektedir. Oluşturulan 14 kombinasyonun koleoptil uzunluğunun kalıtım biçimi ve kombinasyonlar arasında karşılaştırılması Çizelge 5'de verilmiştir. Çizelge incelendiğinde; uzun koleoptilli ve uzun boylu modern varyete olan UK6 ebeveyninin kullanıldığı 6. ve 13. kombinasyonlarda üstün dominantlık gözlenmiştir. Bu kombinasyonların

Çizelge 3. Kombinasyonların koleoptil uzunluğu, primer kök sayısı ve ilk yaprak uzunluğu özelliklerine ait kareler ortalaması ve önem düzeyleri

Table 3. Sum of squares and probability levels of coleoptile lengths, primary root numbers and first leaf lengths of combinations

\begin{tabular}{|c|c|c|c|}
\hline Kombinasyon & $\begin{array}{l}\text { Koleoptil Uzunluğu } \\
(\mathrm{cm})\end{array}$ & $\begin{array}{l}\text { Primer Kök Sayısı } \\
\text { (adet) }\end{array}$ & $\begin{array}{l}\text { İlk Yaprak Uzunluğu } \\
\text { (cm) }\end{array}$ \\
\hline 1 & $1.052^{* *}$ & $0.910^{* *}$ & 1.346 \\
\hline 2 & $3.503^{* *}$ & $0.674^{\star *}$ & 8.832 ** \\
\hline 3 & $2.106^{\star *}$ & $0.924^{* *}$ & 2.757 \\
\hline 4 & $9.276^{* *}$ & $1.464^{* *}$ & $29.841^{* *}$ \\
\hline 5 & $3.051^{*}$ & 0.180 & 5.062 \\
\hline 6 & $0.728^{* *}$ & $0.870^{* *}$ & $4.970^{\star}$ \\
\hline 7 & $4.265^{\star *}$ & $0.317^{*}$ & $35.148^{* *}$ \\
\hline 8 & $1.321^{* *}$ & $0.637^{*}$ & 4.686 ** \\
\hline 9 & $2.775^{\star *}$ & 1.040 & $27.418^{* *}$ \\
\hline 10 & $2.420^{* *}$ & $2.172^{* *}$ & 1.988 \\
\hline 11 & $6.761^{* *}$ & 0.746 & $31.423^{* *}$ \\
\hline 12 & $3.442^{* *}$ & $1.422^{*}$ & 4.458 \\
\hline 13 & $0.798^{*}$ & $1.039 * *$ & 4.054 \\
\hline 14 & $4.453^{* *}$ & $0.959^{* *}$ & $33.837^{* *}$ \\
\hline
\end{tabular}

*, **: Sırasıyla 0.05 ve 0.01 olasılık düzeylerinde önemli.

*,** Significant at 0.05 and 0.01 levels, respectively.

Çizelge 4. Kombinasyonların koleoptil uzunluğu, primer kök sayısı ve ilk yaprak uzunluğu özelliklerine ait korelasyon tablosu ve önem düzeyi

Table 4. Correlation table and probability levels of coleoptile lengths, primary root numbers and first leaf lengths of combinations

\begin{tabular}{lccc}
\hline & $\begin{array}{c}\text { Koleoptil Uzunluğu } \\
(\mathrm{cm})\end{array}$ & $\begin{array}{c}\text { Primer Kök Sayısı } \\
\text { (adet) }\end{array}$ & $\begin{array}{c}\text { Illk YaprakUzunluğu } \\
(\mathrm{cm})\end{array}$ \\
\hline Koleoptil Uzunluğu (cm) & - & 0.427 & $0.964^{* *}$ \\
Primer Kök Sayısı (adet) & & - & 0.431 \\
İlk Yaprak Uzunluğu (cm) & & & - \\
\hline
\end{tabular}

*, **: Sırasıyla 0.05 ve 0.01 olasılık düzeylerinde önemli.

*, ** Significant at 0.05 and 0.01 levels, respectively.

Çizelge 5. Kombinasyonlarda koleoptil uzunluğunun kalıtım biçimi

Table 5. Type of inheritance of coleoptile length in combinations

\begin{tabular}{|c|c|c|c|c|}
\hline $\begin{array}{l}\text { Kombinasyon } \\
\text { Numarası }\end{array}$ & $\begin{array}{c}\text { Uzun } \\
\text { Koleoptilli } \\
\text { Ebeveyn }\end{array}$ & $\begin{array}{c}\text { Kısa } \\
\text { Koleoptilli } \\
\text { Ebeveyn }\end{array}$ & Kalıtım Tipi & $\begin{array}{c}\text { Resiproklar Arası } \\
\text { Fark }\end{array}$ \\
\hline 1 & UK1 & $\mathrm{KK} 1$ & Eksik Dominantlık & Yok \\
\hline 8 & UK1 & KK2 & Eksik Dominantlık & Yok \\
\hline 2 & UK2 & KK1 & Eksik Dominantlık & Resiprok yok \\
\hline 9 & UK2 & KK2 & Eksik Dominantlık & Var \\
\hline 3 & UK3 & KK1 & Eksik Dominantlık & Yok \\
\hline 10 & UK3 & KK2 & Eksik Dominantlık & Var \\
\hline 4 & UK4 & KK1 & Eksik Dominantlık & Var \\
\hline 11 & UK4 & KK2 & Eksik Dominantlık & Yok \\
\hline 5 & UK5 & KK1 & Eksik Dominantlık & Yok \\
\hline 12 & UK5 & KK2 & Eksik Dominantlık & Var \\
\hline 6 & UK6 & KK1 & Üstün Dominantlık & Var \\
\hline 13 & UK6 & KK2 & Üstün Dominantlık & Var \\
\hline 7 & UK7 & KK1 & Eksik Dominantlık & Var \\
\hline 14 & UK7 & KK2 & Eksik Dominantlık & Yok \\
\hline
\end{tabular}


dışındaki diğer 12 kombinasyonda koleoptil uzunluğunun kalıtımı eksik dominantlık olarak saptanmıştır. Rebetzke ve ark. çalışmalarında koleoptil uzunluğu, kalınlığı ve ilk yaprak uzunluğu özelliklerinde ebeveynleri geçen bitkilerin bulunduğunu ve dolayısıyla üstün dominantlık gösteren sonuçlarımızla paralel olarak transgresif bir açılmanın olduğunu belirlemişlerdir.

\section{Sonuc}

Bu çalışmada elde edilen sonuçlar ışığında; eksik dominantlık gösteren kombinasyonların $F_{2}$ generasyonundan kısa boylu ve uzun koleoptilli tek bitkilerin seçilip sonraki generasyonlara götürülmesi ve geliştirilmesi yolu izlenebilir. İncelenen üç özellik arasındaki ilişkiler açısından bakıldığında, koleoptil uzunluğu ile ilk yaprak uzunluğu arasında önemli ve pozitif yönde bir ilişki belirlenmiştir. Bu ilişki, uzun koleoptilli genotiplerde oluşan ilk yaprakların uzunluklarının da daha fazla olacağı, dolayısıyla daha büyük bir yaprak alanına sahip olacakları anlamına gelmektedir. Diğer bir ifadeyle daha uzun koleoptile sahip genotiplerden daha güçlü ve güneş ışığından daha büyük oranda yararlanabilen ve fotosentez oranı daha yüksek genç bitkiler elde edilebilir.

\section{Kaynaklar}

Bai G., Das M.K., Carver B.F., Xu X. and Krenzer E.G., 2004. Covariation for microsatellite marker alleles associated with Rht8 and coleoptile length in winter wheat. Crop Sci. 44: 1187-1194

Byerlee D. and Moya P., 1993. Impacts of International Wheat Breeding Research in Developing World. CIMMYT, Mexico

Chowdhry A.R. and Allan R.E., 1963. Inheritance of coleoptile length and seedling height and their relation to plant height of four winter wheat crosses. Crop Sci., 3: 53-58

Devlet Meteoroloji İşleri Genel Müdürlüğü, 2012. Türkiye'nin 2011-2012 Yılı Kuraklık Analizi, http://www.dmi.gov.tr/FILES/arastirma/20112012-kuraklik.pdf, (Erişim Tarihi: 02.02.2014.)

Evans L.T., 1998. Feeding the Ten Billion: Plant and Population Growth. Cambridge University Press, Cambridge

Feather J.T., Qualset C.O. and Vogt H.E., 1968. Planting depth critical for short statured wheat varieties. California Agriculture, 22: 12-14
Gale M.D. abd Youssefian S., 1985. Dwarfing Genes in Wheat: Progress in Plant Breeding, (Editör:Russell GE), Butterworth-Heinemann. $1-39$

Hakizimana F., Haley S.D. and Turnipseed E.B., 2000. Repeatability and genotype $X$ environment interaction of coleoptile length measurements in winter wheat. Crop Sci., 40: 1233-1237

Hedden P., 2010. Green Revolution Genes, http://5e.plantphys.net/article.php?ch=\&id=35 5, (Erişim Tarihi: 18.12.2013.)

Heisey P.W. and Lantican M.A., 1999. International Wheat Breeding Research in Eastern and Southern Africa, 1996-1997: CIMMYT. The Tenth Regional Wheat Workshop for Eastern, Central and Southern Africa, CIMMYT. 441456

Hoogerndoorn J., Pfeiffer W.H., Rajaram S. and Gale M.D., 1988. Adeptive Aspects of Dwarfing Genes in CIMMYT Germplasm: Proceedings of the Seventh International Wheat Genetics Symposium, (Editör: Miller TE, Koebner RMD), Institute of Plant Science Research, 1093-1100

Keyes G.J., Paolillo D.J. and Sorrells M.E., 1989. The effects of dwarfing genes Rht 1 and Rht2 on cellular dimensions and rate of leaf elongation in wheat. Annals of Botany, 64: 683-690

Mızrak G, 2011. Buğdayın Hikayesi.Türkiye Ziraat Odaları Birliği, Ankara s. 156

Pumpa J., Martin P., McRae F. and Coombes N., 2013. Coleoptile Length of Wheat Varieties, http://www.dpi.nsw.gov.au/_data/assets/pdf file/0006/459006/Coleoptile-length-of-wheatvarieties.pdf, (Erişim Tarihi: 03.10.2013)

Rebetzke G.J., Verbyla A.P., Verbyla K.L., Morell M.K. and Cavanagh C.R., 2014. Use of a large multiparent wheat mapping population Ingenomic dissection of coleoptile and seedling growth. Plant Biotechnology Journal, 219-230

Sağlam S., 2010. Tarla Bitkileri Yetiştirme İlkeleri - II, Ankara Üniversitesi, Ziraat Fakültesi Ders Notları

Singh R.P., Huerta-Espino J., Rajaram S. and Crossa J., 2001.Grain yield and other traits of tall and dwarf Isolines of modern bread and durum wheats. Euphytica, 119: 241-244 